Gut, 1986, 27, 49-54

\title{
Effects of serotonin on the internal anal sphincter: in vivo manometric study in rats
}

\author{
M GOLDBERG, M HANANI, AND S NISSAN
}

From the Department of Surgery and Laboratory of Experimental Surgery, Hadassah University Hospital, Mount Scopus, Jerusalem, Israel

SUMmARY The effects of serotonin (5-hydroxytryptamine, 5-HT) on the internal anal sphincter were studied in anaesthesised rats. Serotonin induced a dose dependent relaxation of the internal anal sphincter. Methysergide blocked this relaxation, but did not affect the rectoanal reflex. Methysergide did not antagonise the actions of cholinergic and adrenergic agonists on the internal anal sphincter. Other 5-HT antagonists such as cyproheptadine, ketanserin, chlorpromazine, amitriptyline and ergotamine failed to reduce or block the internal anal sphincter relaxation due to 5-HT, nor did they alter the rectoanal reflex. Adrenergic and cholinergic antagonists had no effect on the 5-HT-induced relaxation of the internal anal sphincter, suggesting that 5-HT acts upon the internal anal sphincter via a non-adrenergic, non-cholinergic mechanism. Tetrodotoxin reduced or blocked the relaxation of the internal anal sphincter produced by 5-HT, implying that 5-HT acts through neural pathways rather than directly on the muscle. It is concluded that although 5-HT relaxes the internal anal sphincter, it does not participate in the rectoanal reflex.

Serotonin $(5-\mathrm{HT})$ has been proposed as a neurotransmitter in various parts of the alimentary tract acting on both enteric nerves and on the smooth muscles. ${ }^{1}$ Pharmacological studies of 5 -HT have revealed its multiple actions in the gut. Responses of the smooth intestinal muscle to 5-HT are quite variable, depending on the region of the gut and the species examined. ${ }^{23}$ Serotonin acts on enteric ganglia, ${ }^{45}$ thereby activating neurones that release acetylcholine and cause contraction of the longitudinal and circular layers of smooth muscle. ${ }^{67}$

Serotonin also activates non-adrenergic, noncholinergic intrinsic inhibitory neurones, and is therefore able to relax the gut if excitatory neuromuscular transmission is blocked. ${ }^{6-8}$ These results suggest that the role of 5-HT in the enteric nervous system is to serve as the transmitter of interneurones. ${ }^{1}$ Its effect on the gut motor activity have been both excitatory and inhibitory, probably by stimulating different receptor systems. ${ }^{910}$

Burleigh et $a l^{11}$ reported that 5-HT induced contraction of the human internal anal sphincter in vitro, and therefore excluded it as a possible inhibitory neurotransmitter. Rayner, ${ }^{12}$ however,

Address for correspondence: Meir Goldberg MD, Department of Surgery, Hadassah University Hospital, Mount Scopus, Jerusalem 91240, Israel.

Received for publication 19 April 1985 reported that 5-HT relaxed the internal anal sphincter muscle strip of the vervet monkey in organ bath.

Serotonin has been implicated in disturbances of gastrointestinal motility in patients with carcinoid syndrome. In a study of patients with Hirschsprung's disease, Rogawski et $a l^{13}$ reported the absence of serotonergic neurones in the aganglionic colon.

The pharmacology of the internal anal sphincter has been studied in vivo using animal models. ${ }^{12} 14$ No information is available, however, on the actions of 5-HT on the internal anal sphincter in vivo. The aim of this study has been to investigate the effects of 5-HT and its antagonists on the tone of the anus and rectum and the rectoanal reflex in intact rats.

\section{Methods}

RATS

One hundred and five rats of either sex were anaesthesised with ip chloral hydrate $200 \mathrm{mg} / \mathrm{kg}$. The carotid artery and jugular vein were cannulated using a 19G needle catheter. Blood pressure was measured with a transducer connected to the carotid artery and drugs were administered through the jugular vein. Anal and rectal pressures were recorded with a probe containing a proximal rectal balloon and a distal anal balloon which was posi- 
tioned within the lumen of the internal anal sphincter. ${ }^{15}$ The rectoanal reflex was elicited by inflating the rectal balloon with $0.6-0.8 \mathrm{ml}$ air. Pressures were recorded via Statham pressure transducers by a Hewlett-Packard 7745A recorder. When needed, a respirator was used to maintain adequate ventilation. The administration of each drug was repeated several (five to 10) times in a given experiment. There was sufficient time between injections to allow for full recovery.

Drugs used were: serotonin (creatinine sulphate complex), tryptamine hydrochloride, cyproheptadine hydrochloride, amitriptyline hydrochloride, 1,1-dimethyl 4-phenylpiperazinium iodide (DMPP), carbamylcholine chloride (carbachol), isoprenaline hydrochloride, noradrenaline bitartrate, hexamethonium bromide and tetrodotoxin (TTX), all from Sigma. Methysergide dimaleate (Sandoz), phenoxybenzamine hydrochloride (SK\&F), propranolol hydrochloride (Abic), atropine sulphate (Teva), ketanserin (Janssen).

\section{Results}

EFFECTS OF 5-HT AND TRYPTAMINE

Injection of serotonin (5-HT) in the range of 3-50 $\mu \mathrm{g} / \mathrm{kg}$ relaxed the internal anal sphincter in all 105 rats (Fig. 1). The magnitude of the relaxation is expressed by multiplying the response amplitude by its duration and is dose-dependent (Fig. 2). In the

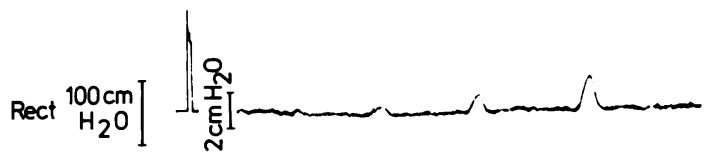

IAS
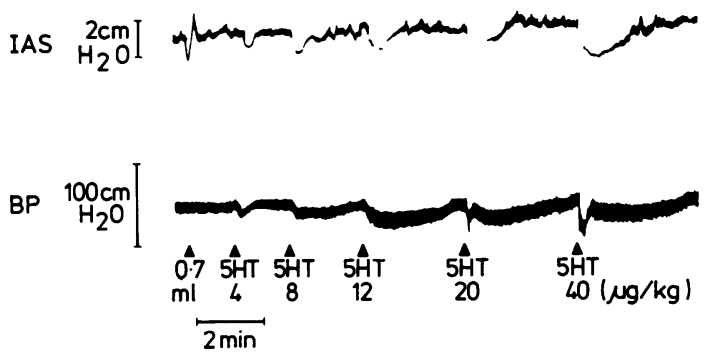

Fig. 1 Actions of serotonin (5-HT) on the rectum (RECT) and internal anal sphincter (IAS); pressure recording in the rat. Inflation of the rectal balloon with $0.7 \mathrm{ml}$ of air, produced IAS relaxation - the recto-anal reflex. 5-HT relaxed the IAS and contracted the rectum in a dose dependent manner. Note the decrease in blood pressure $(B P)$ caused by 5-HT. Concentrations are given in $\mu \mathrm{g} / \mathrm{kg}$.

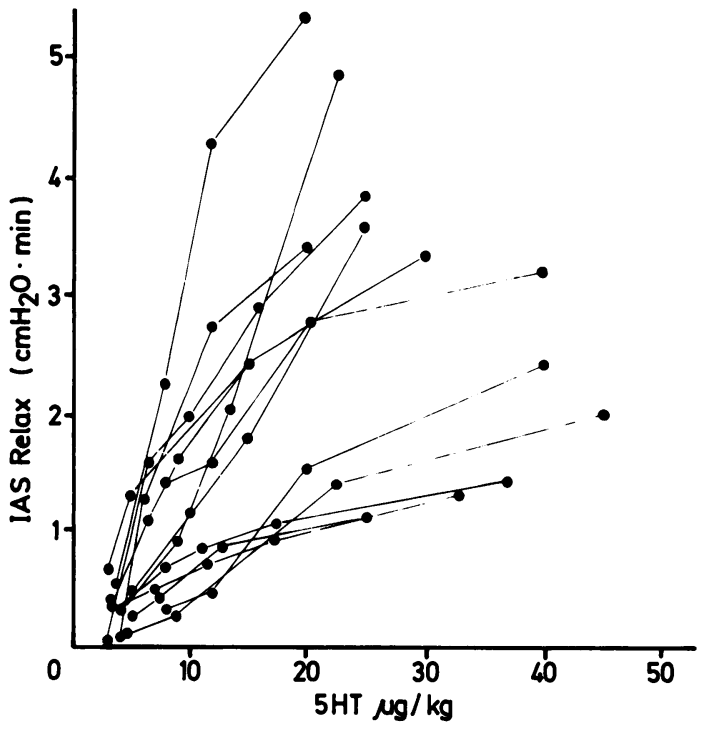

Fig. 2 Dose dependent curves for the 5-HT-induced relaxation of the IAS, obtained in 13 rats. The 5-HT effect is expressed by multiplying the response amplitude $\left(\mathrm{cm} \mathrm{H}_{2} \mathrm{O}\right.$ ) by its duration ( $\mathrm{min}$ ) and it is dose dependent. Note that in spite of the absolute variations, the threshold and range of the responses are similar for most of the experiments.

rectum, 5-HT caused contraction (70\% of rats) which was likewise dose dependent (Fig. 1). Repeated 5-HT doses of up to $100 \mu \mathrm{g} / \mathrm{kg}$ (accumulated dose), did not change the amplitude or duration of the relaxation of the internal anal sphincter, compared with a control response.

Tryptamine $(25-1000 \mu \mathrm{g} / \mathrm{kg}$ ) elicited a dose dependent relaxation of the internal anal sphincter (five rats) and was $50-100$ times less potent than $5-\mathrm{HT}$ in producing internal anal sphincter relaxation. This relation was determined by injecting 5-HT and tryptamine at varying doses and then comparing the doses needed to produce similar responses (Fig. 3 ). The blood pressure was transiently reduced after 5-HT administration. In contrast, tryptamine caused an increase in blood pressure followed by a decrease. Similar observations have been made in several animal species, and it has been suggested that 5-HT and tryptamine act via different receptors. ${ }^{16}$

EFFECTS OF 5-HT ANTAGONISTS

Methysergide $(32 \mu \mathrm{g} / \mathrm{kg})$, reduced the effect of 5-HT upon the internal anal sphincter by about $50 \%$ (Fig. 4). At higher doses $(200 \mu \mathrm{g} / \mathrm{kg}, \mathrm{n}=12)$ it completely blocked the 5-HT-induced relaxation of the internal anal sphincter (Fig. 4). It did not alter the resting 


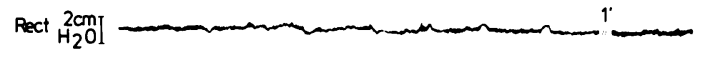

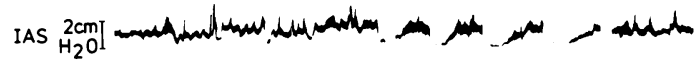

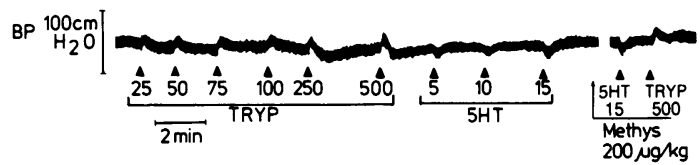

Fig. 3 Comparison of the effect of tryptamine (TRYP) and 5-HT on the IAS. Increased doses of tryptamine, up to $500 \mu \mathrm{g} / \mathrm{kg}$, produced IAS relaxation and increase in blood pressure (BP). 5-HT was 50-100 times more potent than tryptamine in producing IAS relaxation. The effects of both 5-HT and tryptamine on the IAS, were blocked by methysergide.

tone of the rectum and anus and the rectoanal reflex (Fig. 4).

The effects of cholinergic and adrenergic agonists such as: DMPP, carbachol, phenylephrine and isoprenaline upon the internal anal sphincter were not affected by methysergide $(200-400 \mu \mathrm{g} / \mathrm{kg})$. Administration of other 5-HT antagonists: cyproheptadine (up to $4 \mathrm{mg} / \mathrm{kg}, \mathrm{n}=7$ ), ketanserin (up to 6 $\mathrm{mg} / \mathrm{kg}, \mathrm{n}=6$ ), chlorpromazine (up to $0.1 \mathrm{mg} / \mathrm{kg}$, $\mathrm{n}=4$ ), amitriptyline (up to $0.6 \mathrm{mg} / \mathrm{kg}, \mathrm{n}=3$ ) and ergotamine (up to $0.25 \mathrm{mg} / \mathrm{kg}, \mathrm{n}=4$ ) failed to affect the relaxation of the internal anal sphincter induced by 5-HT. The anal and rectal tones and the rectoanal reflex were also not affected.

\section{EFFECTS OF ADRENERGIC AND CHOLINERGIC ANTAGONISTS}

The actions of 5-HT may be mediated by the release of other neurotransmitters such as noradrenaline or acetylcholine. To test this possibility, adrenergic and cholinergic antagonists were given before 5-HT administration. The alpha adrenoreceptor antagonist phenoxybenzamine $(250 \mu \mathrm{g} / \mathrm{kg})$ blocked the effect of noradrenaline $(1.5 \mu \mathrm{g} / \mathrm{kg}, \mathrm{n}=7)$ but did not affect the internal anal sphincter relaxation induced by 5 -HT (Fig. 5a).

The beta adrenoreceptor antagonist propranolol $(1 \mathrm{mg} / \mathrm{kg}, \mathrm{n}=5)$ blocked the effect of isoprenaline ( 6 $\mu \mathrm{g} / \mathrm{kg}$ ) on the internal anal sphincter, but failed to affect the relaxation of the internal anal sphincter produced by 5-HT (Fig. 5b). The muscarinic cholinergic antagonist atropine $(0.5 \mathrm{mg} / \mathrm{kg}, \mathrm{n}=3)$ blocked the effect of carbachol $(2 \mu \mathrm{g} / \mathrm{kg})$ but did not change the relaxation of the internal anal sphincter to 5-HT administration (Fig. 6). Hexamethonium, a nicotinic cholinergic antagonist, $(2.4 \mathrm{mg} / \mathrm{kg}, \mathrm{n}=5)$ blocked the effect of DMPP $(60 \mu \mathrm{g} / \mathrm{kg})$ upon the internal anal sphincter, but had no effect on the relaxation of the internal anal sphincter produced by 5-HT (Fig. 6b).

EFFECT OF TETRODOTOXIN

Receptors for 5-HT have been found on both muscle

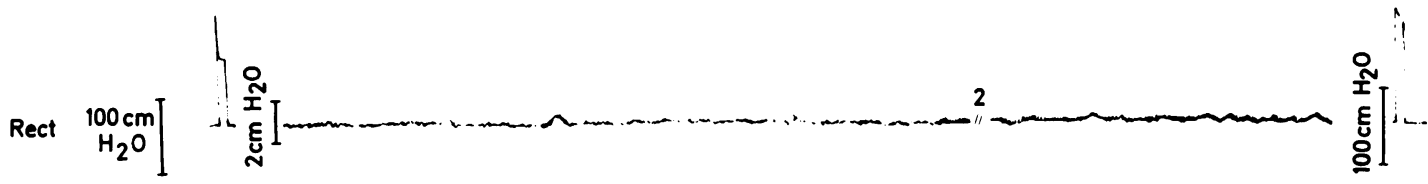

IAS $\quad \begin{aligned} & 2 \mathrm{~cm} \\ & \mathrm{H}_{2} \mathrm{O}\end{aligned}$

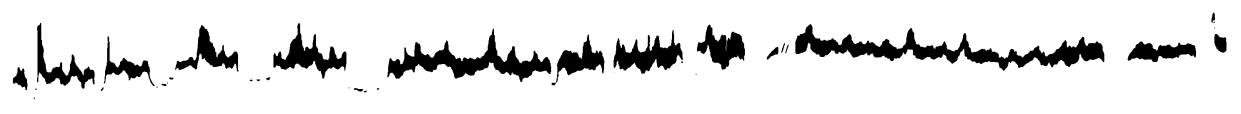

BP

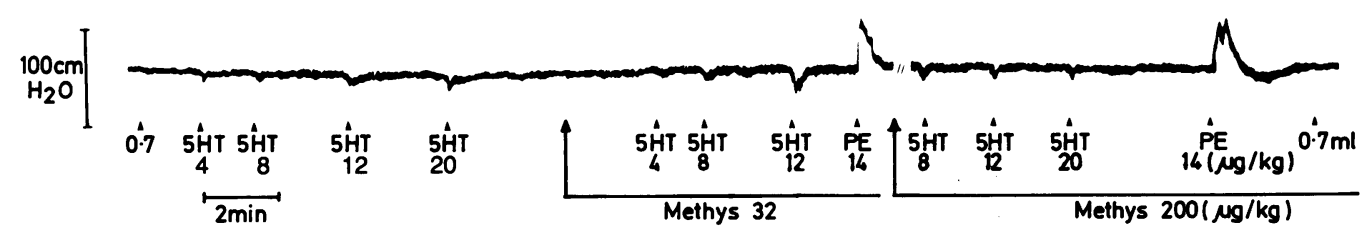

Fig. 4 Methysergide antagonism of 5-HT actions on the IAS. Methysergide (METHYS) at a low dose of $32 \mu \mathrm{g} / \mathrm{kg}$ reduced the 5-HT-induced IAS relaxation. At a dose of $200 \mu \mathrm{g} / \mathrm{kg}$ methysergide completely eliminated the response to 5-HT. During this blockade of 5-HT effects, the rectoanal reflex remained unchanged. Phenylephrine (PE) was given to show that the IAS muscle retains its ability to relax in the presence of methysergide. 
(a) Rect $\mathrm{H}_{2} \mathrm{O} \mathrm{OI}$ IAS
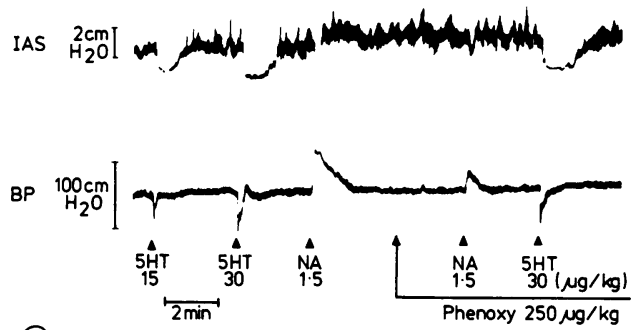

(b)

Rect $2 \mathrm{~cm}[\sim 2 \cdots$
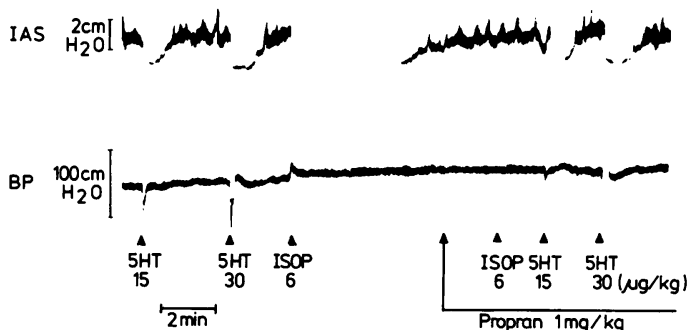

Fig. 5 Effects of adrenergic antagonists on the IAS response to 5-HT: (a) the effect of alpha adrenergic blockade. Noradrenaline (NA) caused brief relaxation of the IAS. Phenoxybenzamine (PHENOXY) antagonised the effect of $N A$ but did not alter the response to 5-HT. (b) Effect of beta adrenergic blockade. Isoprenaline (ISOP) caused a prolonged relaxation of the IAS, which was blocked by propranolol (PROPRAN). The response to 5-HT was not affected by propranolol.

and nerve cells. To distinguish between these two sites of action, the nerve blocker tetrodotoxin was used. Tetrodotoxin, in an accumulated dose of 2.8 to $18.4 \mu \mathrm{g} / \mathrm{kg}$ was applied to eight rats. In all eight rats tetrodotoxin blocked or reduced the internal anal sphincter relaxation to 5-HT administration in a dose dependent pattern (Fig. 7). As shown in Fig. 7, a dose of $3 \mu \mathrm{g} / \mathrm{kg}$ of tetrodotoxin completely blocked the effect of $5-\mathrm{HT}(3$ and $6 \mu \mathrm{g} / \mathrm{kg}$ ) on the internal anal sphincter, while it reduced the internal anal sphincter relaxation induced by $9 \mu \mathrm{g} / \mathrm{kg}$ of 5-HT. In order to block the effect of higher 5-HT doses $(10-40 \mu \mathrm{g} / \mathrm{kg})$ increased doses of tetrodotoxin $(10-18.4 \mu \mathrm{g} / \mathrm{kg})$ were used.

Tetrodotoxin blocked the internal anal sphincter response to DMPP $(60 \mu \mathrm{g} / \mathrm{kg})$ which is nerve mediated, while it had no effect upon internal anal
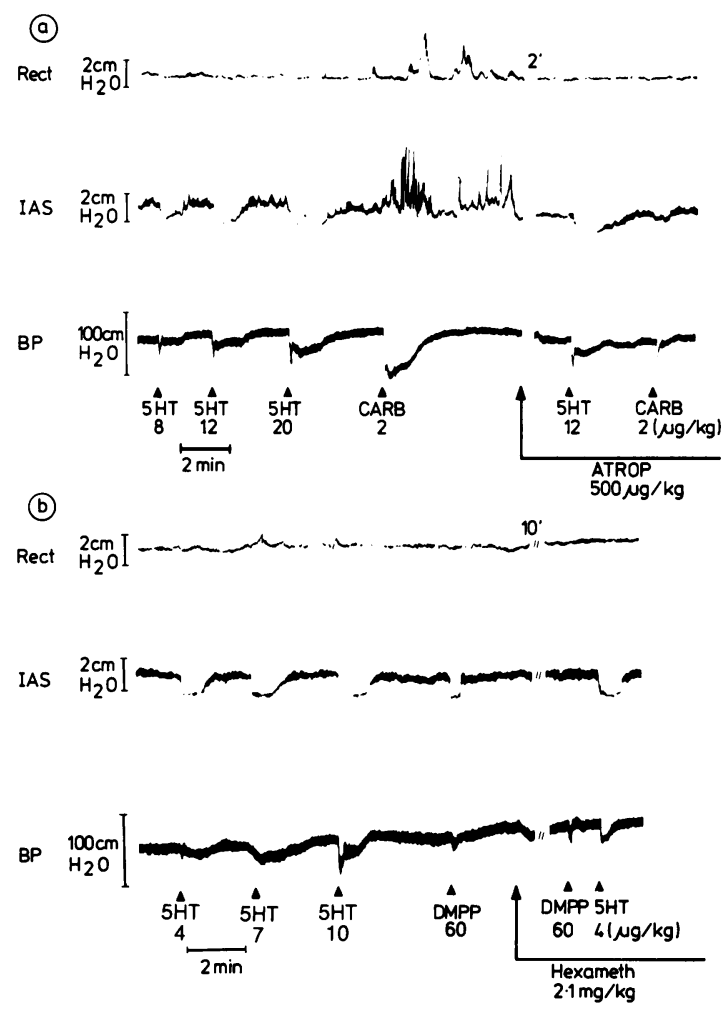

Fig. 6 Effect of cholinergic antagonists on the IAS reponse to 5-HT: (a) muscarinic blockade by atropine (ATROP). Carbachol (CARB) contracted the IAS and the rectum. After the applicaiton of atropine this contraction was blocked, but the 5-HT response was not affected. (b) nicotinic blockade by hexamethonium (HEXAMETH). The nicotinic cholinergic agent DMPP induced IAS relaxation. Hexamethonium blocked this effect but did not change the response to 5-HT.

sphincter relaxation produced by phenylephrine (14 $\mu \mathrm{g} / \mathrm{kg}$ ) which presumably acts directly on the smooth muscle (Fig. 7).

\section{Discussion}

Serotonin (5-HT) displays a multiplicity of actions as a potential neurotransmitter in the gastrointestinal tract. ${ }^{117} 18$ In the present in vivo study in rats, the internal anal sphincter underwent relaxation by 5-HT. This finding correlates with the in vitro study by Rayner ${ }^{12}$ who found that the internal anal sphincter of the vervet monkey is relaxed by $5-\mathrm{HT}$. In contrast to the present results, Burleigh $e t$ al ${ }^{11}$ reported that 5-HT induced contraction of the human internal anal sphincter in organ bath. The reason for this difference is not clear; it may be 
Rect

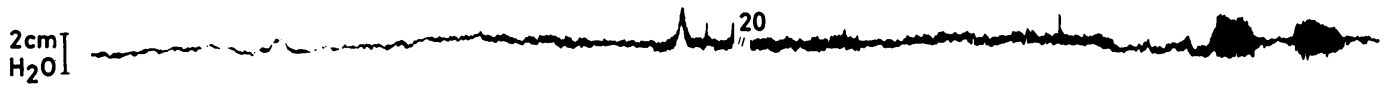

IAS
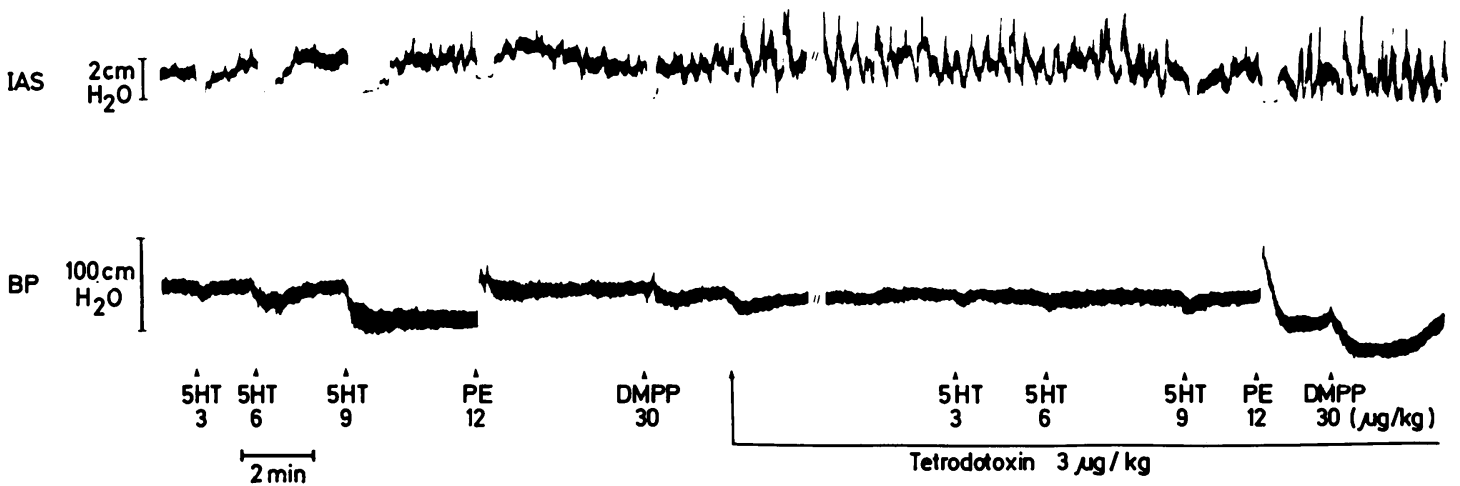

Fig. 7 Actions of tetrodotoxin (TTX) on the IAS relaxation evoked by 5-HT. Effects of DMPP, which are nerve mediated, were blocked by TTX whereas phenylephrine (PE) which acts directly on the muscle was still effective. During nerve blockade by TTX the relaxations caused by $5-H T(3$ and $6 \mu \mathrm{g} / \mathrm{kg})$ were completely prevented and the response to $5-H T(9 \mu \mathrm{g} / \mathrm{kg})$ was greatly reduced. Note the increase in the spontaneous activity of the IAS after TTX injection.

because of the species difference, or because of the experimental conditions (in vitro vs in vivo). It should be mentioned that Burleigh et al did not specify the site of 5-HT actions in the human internal anal sphincter, which may be the muscle itself. Our experiments on the rat indicate that 5-HT acts via a neural pathway.

In the present work, 5-HT produced in the majority of cases $(70 \%)$, a dose dependent rectal contraction. Our results show that $5-\mathrm{HT}$ was $50-100$ times more potent than tryptamine in producing internal anal sphincter relaxation. Methysergide was the only effective antagonist, while ketanserin and cyproheptadine failed to block 5-HT actions. This indicates that the receptors mediating 5-HT actions in the internal anal sphincter may be similar to those described as $5-\mathrm{HT}_{1}$ central receptors. ${ }^{19}$ The relaxation of the internal anal sphincter after 5-HT administration was completely blocked by methysergide, which failed to affect the rectoanal reflex. It may therefore be concluded that 5-HT does not act as an inhibitory neurotransmitter in the rectoanal reflex.

It has been proposed that methysergide at high concentrations is comparably effective in antagonising the actions of carbachol, DMPP and histamine on the intestine. ${ }^{17}$ The effect of methysergide on cholinergic and adrenergic agonists activity was examined, using the same concentrations that blocked the internal anal sphincter response to 5-HT. Methysergide had no effect upon the internal anal sphincter response to administration of: carbachol,
DMPP, isoprenaline and phenylephrine and seems therefore to act as a selective 5-HT antagonist.

It has been shown that during exposure of isolated intestinal segments to 5-HT, the sensitivity to this drug is diminished. ${ }^{7}$ The effect is dependent on the presence of 5-HT in the organ bath and it is reversed on washing. Such a tachyphylactic effect has not been observed in our experiments. A possible explanation for this finding is that in the intact animal, the 5-HT level is readily reduced by the effective uptake mechanism for this substance. ${ }^{1}{ }^{17}$

Serotonin can stimulate ${ }^{7}$ or antagonise ${ }^{20}$ the release of acetylcholine in the gut. This raises the possibility that 5-HT acts on the internal anal sphincter by modifying the release of acetylcholine or perhaps of other transmitters such as noradrenaline. Adrenergic and cholinergic agents were shown to modify the activity of the rat internal anal sphincter. ${ }^{21}$ To examine this point, cholinergic and adrenergic antagonists were used. Administration of such antagonists (atropine, hexamethonium, phenoxybenzamine and propranolol) failed to affect the internal anal sphincter relaxation produced by 5-HT, as well as the tone of the anus and rectum. This shows that the action of 5-HT is not mediated by cholinergic or adrenergic transmitters.

Methysergide may antagonise muscular ${ }^{6}{ }^{10}$ as well as neural ${ }^{20} 22$-HT receptors. In order to eliminate the possible neural effect of 5-HT, tetrodotoxin was used. Tetrodotoxin blocked or reduced the effect of 5-HT on the internal anal sphincter. This finding suggests that 5-HT causes internal anal sphincter 
relaxation via activation of neural rather than muscular receptors. A similar effect of tetrodotoxin on 5-HT neural receptors in the gut was observed by other investigators. ${ }^{712} 2023$ It also seems reasonable to conclude that methysergide blocks the 5-HT effect by acting at the neural level. The latter conclusion is supported by the studies of Wood and Mayer $^{22}$ and North et $a l^{20}$ who observed the direct effect of methysergide on myenteric neurones.

In conclusion, the present results indicate that 5-HT stimulates a non-adrenergic, non-cholinergic inhibitory neural pathway with a consequent relaxation of the internal anal sphincter in rats. It is not the neurotransmitter, however, that causes the relaxation of the internal anal sphincter during the rectoanal reflex.

This work was supported by grants from the Chief Scientist's Office, Ministry of Health, Israel and the Joint Research Fund of the Hebrew University and Hadassah. We thank Sandoz Ltd, Switzerland, for a gift of methysergide and Janssen Pharmaceutica, Belgium for a gift of ketanserin.

\section{References}

1 Gershon MD. The enteric nervous system. Ann Rev Neurosci 1981; 4: 227-72.

2 Gershon MD. The effects of tetrodotoxin on innervated smooth muscle preparations. $\mathrm{Br} J$ Pharmacol 1967; 29: 259-79.

3 Moen H, Ertresvaag K, Gerner T. Motor responses to serotonin in isolated guinea pig fundus and antrum. Scand J Gastroenterol 1983; 18: 145-9.

4 Gaddum JH, Picarelli ZP. Two kinds of tryptamine receptors. Br J Pharmacol 1957; 12: 323-8.

5 Brownlee G, Johnson ES. The site of the 5-hydroxytryptamine receptor on the intramural nervous plexus of the guinea pig isolated ileum. Br J Pharmacol 1963; 21: 306-22.

6 Drakontides AB, Gershon MD. 5-HT receptors in the mouse duodenum. Br J Pharmacol Chemother 1968; 33: $480-92$.

7 Costa M, Furness JB. The sites of action of 5-HT in nerve muscle preparations from the guinea-pig small intestine and colon. Br J Pharmacol 1979; 65: 237-48.

8 Bulbring E, Gershon MD. 5-Hydroxytryptamine participation in vagal inhibitory innervation of the stomach. J Physiol Lond 1967; 192: 823-46.
9 Sakai K, Shiraki Y, Tatsum I, Tsuju K. The actions of 5-hydroxytryptamine and histamine on the isolated ileum of the tree shrew (Tupaiaglis). Br J Pharmacol 1979; 66: 405-8.

10 Rattan S, Goyal RK. Effects of 5-hydroxytryptamine on the lower esophageal sphincter in vivo. J Clin Invest 1977; 59: 125-33.

11 Burleigh DE, D'Mello A, Parks AG. Responses of isolated human anal sphincter to drugs and electrical field stimulation. Gastroenterology 1979; 77: 484-90.

12 Rayner V. Characteristics of the internal anal sphincter and the rectum of the Vervet monkey. J Physiol (Lond) 1979; 286: 383-99.

13 Rogawski MA, Goodrich JT, Gershon MD, Touloukian RJ. Hirschsprung's disease: absence of serotoninergic neurons in the aganaglionic colon. $J$ Pediatr Surg 1978; 13: 608-15.

14 Garrett JR, Howard ER, Jones W. The internal anal sphincter in the cat: a study of the nervous mechanisms affecting tone and reflex activity. J Physiol 1974; 243: $153-66$.

15 Vinograd I, Hanani M, Hadary A, Nissan S. An animal model for studying the physiology and pharmacology of the anal sphincter. Israel J Med Sci 1983; 19: 100.

16 Erspamer V. Peripheral physiological and pharmacological actions of indoleaklylamines. In: Erspamer $\mathrm{V}$, ed. Handbook of experimental pharmacology, vol 29. Berlin: Springer, 1966: 245-359.

17 Furness JB, Costa M. Identification of gastrointestinal neurotransmitters. In: Bertaccini G, ed. Handbook of experimental pharmacology, vol 59/1. Berlin: Springer, 1982: 383-462.

18 Misiewicz JJ, Waller SL, Eisner M. Motor responses of human gastrointestinal tract to 5-hydroxtryptamine in vivo and in vitro. Gut 1966; 7: 208-16.

19 Peroutka SJ, Noguchi M, Tolner DJ, Allen GS. Serotonin-induced contraction of canine basilar artery: mediation by $5-\mathrm{HT}_{1}$ receptors. Brain Res 1983; 259: 327-30.

20 North RA, Henderson G, Katayama Y, Johnson SM. Electrophysiological evidence for presynaptic inhibition of acetylcholine release by 5-hydroxtryptamine in the enteric nervous system. Neuroscience 1980; 5: 581-6.

21 Nissan S, Vinograd I, Hadary A et al. Physiological and pharmacological studies of the internal anal sphincter in the rat. J Pediatr Surg 1984; 19: 12-4.

22 Wood JO, Mayer CD. Serotoninergic activation of tonic-type enteric neurons in guinea-pig small bowel. $J$ Neurophysiol 1979; 42: 582-93.

23 Burks TF. Mediation by 5-hydroxytryptamine of morphine stimulant action in dog intestine. J Pharmacol Exp Ther 1973; 185: 530-9. 